\title{
Research on Self-organization Evolution Mechanism of Chao Lake Environmental Protection Policy
}

\author{
Yuting Xuan ${ }^{1 *}$ \\ 1. School of Public Affairs, University of Science and Technology of China 96 Jinzhai Road,Hefei \\ 230026, the People's Republic of China \\ * E-mail of the corresponding author: xuanyt@ mail.ustc.edu.cn
}

DOI: $10.7176 / \mathrm{DCS} / 8-10-54$

\begin{abstract}
The environmental protection policy is a complex nonlinear system with spontaneous spontaneity and selfadaptation. Its evolution process cannot be fully explained by the existing policy change theory. Since the 1960s, Self-organization Theory of systems science has opened up a new path to the study of complex systems. Selforganization Theory including: Dissipative Structure Theory; Synergetics; Chaotic Theory; Hypercycle Theory; Fractal Theory; Morphogensis Theory. In this paper, Self-organization Theory is introduced into the framework of environmental protection policy change. The Chao Lake is selected as the research object. Based on the analysis of the evolution process of Chao Lake environmental protection policy, the self-organization mechanism of policy evolution is analyzed, and the result is used to predict the development trend of the policy.
\end{abstract}

Keywords: Environmental Protection Policy, Evolution, Self-organization Theory, Chao Lake

\section{Introduction}

As the largest developing country in the world, China has achieved remarkable achievements in economic construction since the reform and opening up. The extensive style of economic growth nevertheless created many environmental problems, including soil desertification, water quality degradation, and air pollution. These environmental problems not only significantly depress people's heath and quality of life but also corrode economic milestones. To balance the contradiction between economic development and environmental quality, the Chinese government has long paid attention to the protection of the environment and introduced relevant policies. At present, the research on these environmental protection policies by the government and academia focuses on the static evaluation of its implementation effect, and few research have included it in the dynamic evaluation of the framework of policy change. Therefore, the selection of appropriate dynamic evaluation tools is of great significance for analyzing the evolution process and mechanism of environmental protection policies and predicting their future development trends.

Currently, several dominant policy change theories include: Advocacy Coalition Framework Theory (P. A. Sabatier,1998);Multiple-Streams Framework Theory（John W. Kingdom, 2004）;Punctuated Equilibrium Theory (S. Walgrave\& F. Varone,2008). Under the framework of these theories, the change of environmental protection policy is a passive change, which is caused by changes in the social environment and the natural environment. In fact, environmental protection policy is a complex nonlinear system with spontaneous spontaneity and self-adaptation. These theories cannot fully explain the process of policy evolution. Since the 1960s, the self-organization theory of systems science has opened up a new path to the study of complex systems. This paper introduces self-organization theory into the framework of environmental protection policy change, selects Chao Lake as the research object, analyse the self-organization evolution mechanism of environmental protection policy of Chao Lake, and the result is used to predict the development trend of the policy.

\section{Methodology}

Professor Qian, X.S. pointed out that the system itself can move into an ordered structure, which can be called self-organization. This theory can also be called Self-organization Theory (Qian,1981). Self-organization Theory including: Dissipative Structure Theory; Synergetics; Chaotic Theory; Hypercycle Theory; Fractal Theory; Morphogensis Theory. Among of them, Dissipative Structure Theory reveals the conditions of self-organization evolution, Synergetics reveals the dynamics of self-organization evolution, and Chaotic Theory reveals the path and direction of self-organization evolution.

The reason why we use Self-organization Theory to analyze the evolution process and mechanism of Chao Lake 
environmental protection policy is because the theory changes the system from static to dynamic, from the research of existence to the study of process, using systematic thinking. Solving the problem reflects the integrity, complexity and dynamics of the Chao Lake environmental protection policy system.

\section{Evolution Process of Chao Lake Environmental Protection Policy}

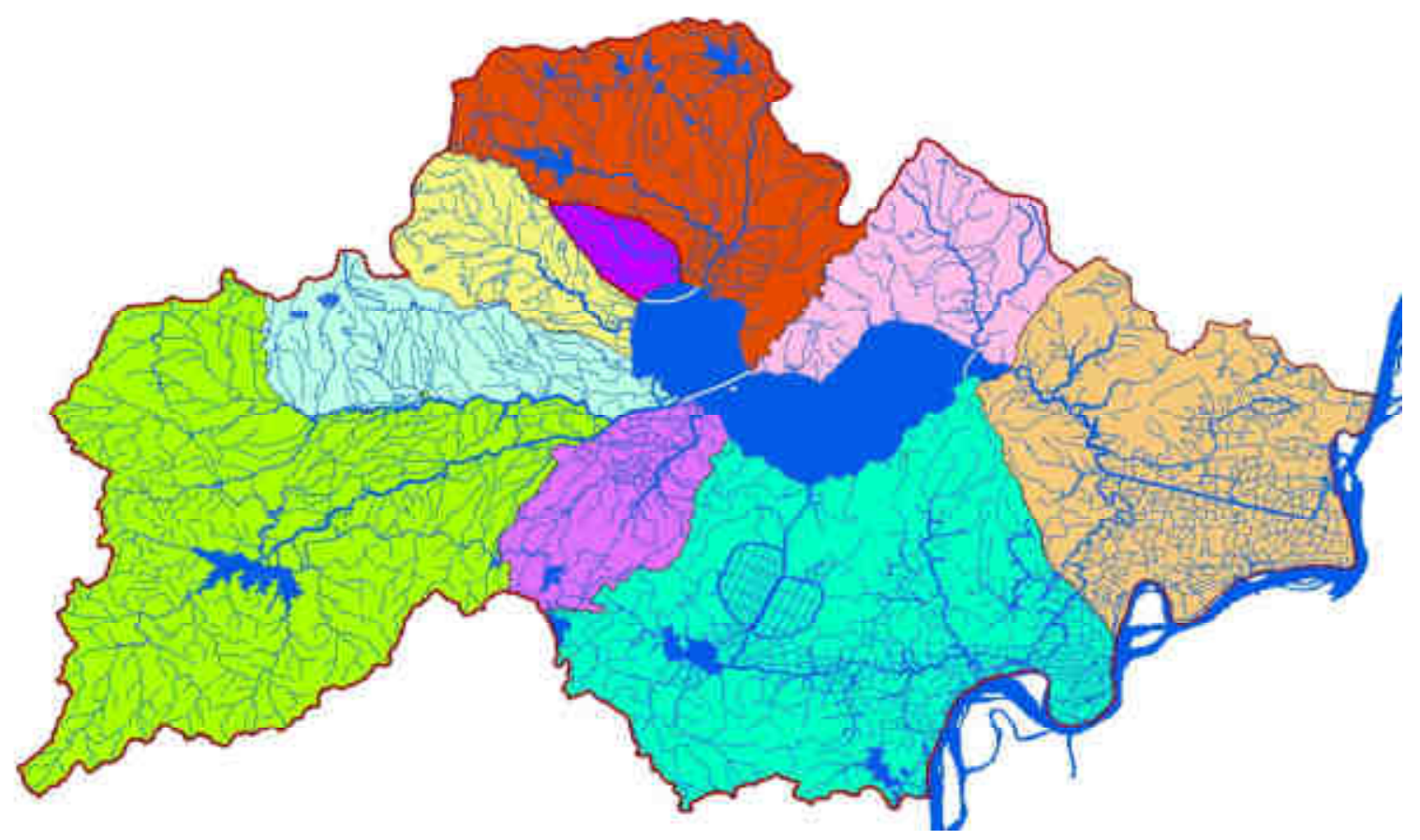

Figure 1. Chao Lake Water Distribution Map

\section{1 basic information of Chao Lake}

Chao Lake is one of the five largest freshwater lakes in China. The lake area is $760 \mathrm{~km} 2$, the coastline is $181 \mathrm{~km}$ long, and the drainage area is $13350 \mathrm{~km} 2$. There are a total of 33 rivers in the basin, of which the main rivers into the lake are the Nanfei River, the Fenli River, the Pai River, the Weihe River, the Fengle River, the Hangyong River, the Baishi Tianhe River in the west, and the Zhaohe River in the south. Eight rivers radiate into the Chao Lake in a radial direction, and enter the Yangtze River through the Yuxi River in the east (Figure 1). At the beginning of the founding of the People's Republic After the Yuxi Gate and Chao Gate were built in the 1960s, Chao Lake gradually changed from a water-based shallow-water lake into a manually controlled semi-closed water area, coupled with population growth, industrial economic development, and excessive fertilization of agricultural planting. Factors, the water pollution of the lake is gradually increasing. In the 1980s, Chao Lake was seriously polluted. The comprehensive water quality of the whole lake was lower than the Class III standard. Some waters were IV or V. The species of fish and shrimp decreased greatly. By the mid-1990s, the lake had become seriously eutrophic. The water quality of the lake is inferior to the V category, and the concentrations of nitrogen and phosphorus have exceeded the standard. It has been listed as the "three rivers and three lakes" in the country. Since 2005, the water quality of Chao Lake has gradually improved. From 2014 to 2016 for three consecutive years, the statistics of Anhui Province Environmental Status Bulletin shows that the average water quality of Chao Lake is Grade IV, mildly polluted and mildly eutrophic. The improvement of the water quality of Chao Lake is consistent with the continuous improvement of the environmental protection policy of Chao Lake and the gradual trend towards stability.

\subsection{Evolution Process of Chao Lake Environment Protection Policy}

The development of Chao Lake environment protection policy is divided into four stages (Figure 2):

(1) exploration stage (1954-1985)

The sprouting stage of the environmental protection policy is fragmented. In 1954, the first Chao Lake Environmental Protection Management Agency - Chao District was established. In 1971, Chao Lake and Zhan'an District set up the Chao Lake Management Office, and in the following year promulgated the "Chao Lake 
Management Regulations" (for trial implementation), clear the management system, management fees and tax system, provides the waters of environmental protection Such as fishing, fishing, fishing, fishing and aquatic plants. In 1979, the revocation of the lake management, Anhui Chao Management Committee Office (also known as Chao Development Company in Anhui Province) was established, the following year promulgated the "Chao management approach" to clarify the proliferation protection measures to limit fishing net, Prohibited to poison, fish, electric catch.

(2) establishment stage (1986-1993)

On August 29, 1987, the Anhui Provincial People's Congress promulgated the " Chao Lake Water Resource Protection Regulations " (1987), which mainly includes the following aspects: First, the protection of Chao Lake Water Resources, is a detailed list of prohibited sexual behavior in the protection zone; the second is a clear regulatory body for the provincial environmental protection Office of urban and rural construction, the local government is responsible for implementation; third is to establish a deadline for pollution discharge standards old system, the new system as well as three simultaneous sources Sewage permit system; four is a clear incentive measures.

(3) formation stage (1994-2004)

A larger number of environmental policy at this stage, including: "Anhui Provincial Government's decision on strengthening the Huai River, Chao Lake Water Pollution Control "(1994); "Anhui Provincial Government's decision on enhancing environmental protection work" (1997), "Chao Lake Water Pollution Control Ninth FiveYear Plan and the 2010 Plan" (1997), "Chao Lake Water Pollution Prevention Regulations" (1998), "Chao Lake Water Pollution Control" (2005) and the " "Approval of the State Council on the 10th Five - Year Plan for Water Pollution Prevention and Control in Chao Lake " (2003). Mainly focused on the following aspects: First, establish environmental protection department is responsible for unified supervision, the relevant departments in accordance with their respective regulatory responsibilities of the management system; the second is to monitor the implementation of zoning and construction project environmental impact assessment system water environmental protection function zones; third is to establish Chao Lake Water Pollution Prevention Fund. Fourth, through the promotion of cleaner production, eliminate backward production capacity, waste water and resource treatment and other measures to control pollution; Fifth, the implementation of four protected areas of water quality management objectives.

(4) deepening stage (2005 to present)

With the Chao Lake environmental issues have been transformed into sustainable development issues, environmental protection policy has deepening into sustainable development policy: In 2008, the Ministry of Environmental Protection issued a direct focus on watershed, "the Huai River, Hai River, Liao River, Chao and Dian Lake, the upper reaches of the Yellow River, etc. Water pollution prevention and control plan (2006-2010) ", no longer use the form of approval of the State Council. August 22, 2011, Anhui Province to revoke the prefecture-level Chao City, the original Chao City under the jurisdiction of a district four counties were classified as Hefei, Ma'an Shan, Wuhu 3 city jurisdiction, Chao Lake since been inside lake of Hefei. In 2012, the Ministry of Environmental Protection issued a "major basin water pollution control plan (2011-2015)", Chao Lake as a water pollution control unit was included in the overall planning. In 2014, Anhui Provincial People's Congress on the implementation of 16 years has been "Chao Lake Water Pollution Prevention Regulations" for a comprehensive revision: First, Chao Lake environmental protection one or two protected areas of the specific scope; Second, the establishment of Hefei municipal government on environmental protectional protection is responsible for the total responsibility, the provincial environmental protection departments unified supervision, the provincial Chao Authority according to the supervision of the management system; third is to develop strict pollution prevention and control objectives and standards; four is to strengthen the pollution control and ecological management; Penalties, known as "the most strict in the history "(Guo,2014). 


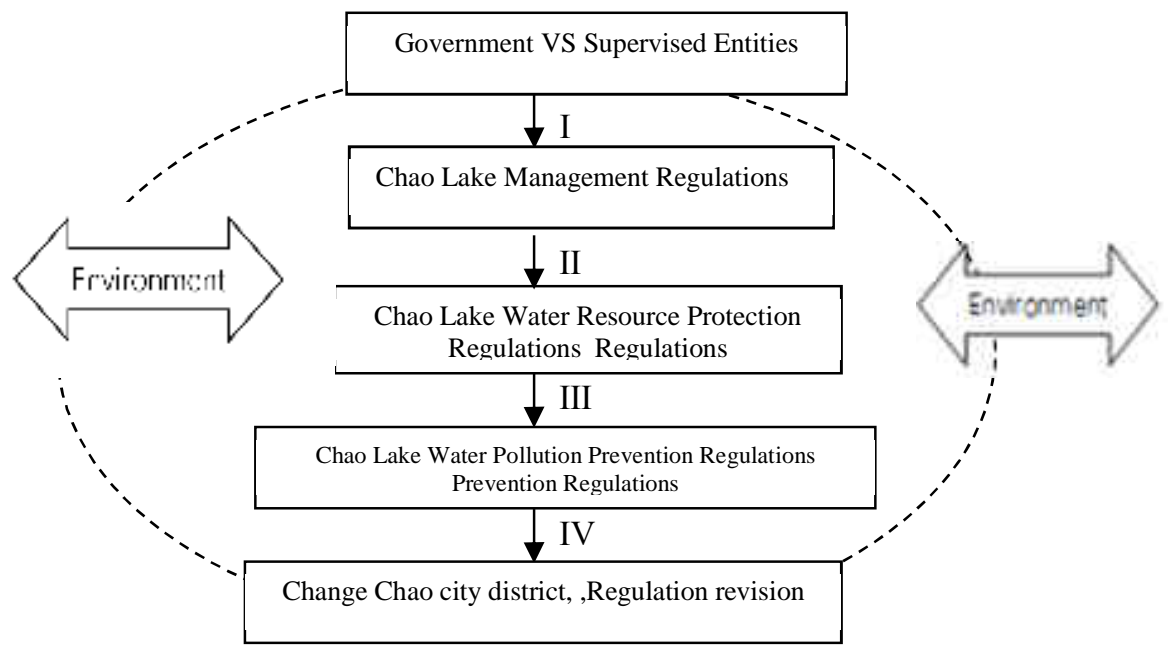

Figure 2. Evolution Process of Chao Lake Environmental Protection Policy

\section{Self-organization Evolution Mechanism of Chao Lake Environmental Protection Policy}

\section{1 application of Self-organization Theory in Evolution of Chao Lake Environmental Protection Policy}

Haken, the founder of synergy, defines "self-organization" as: If a system does not have specific external interference in the process of obtaining spatial, temporal or functional structure, we say that the system is selforganizing. The term "specific" here means that the structure or function is not imposed on the system by the outside world, but the outside world acts on the system in a non-specific way. We believe that the evolution of Chao Lake's environmental protection policy is closely related to the self-organization mechanism. Corresponding to the evolution process of Chao Lake environmental protection policy shown in Figure 3, there is a self-organizing evolution mechanism of Chao Lake environmental protection policy (Figure 3). The abscissa indicates the external control parameters of the system, that is, the extent to which the system deviates from the effective and equilibrium state, and the ordinate indicates the evolution state of the Chao Lake environmental protection policy(H.Haken,1991).

Evolution State of Chao Lake Environmental Protection Policy

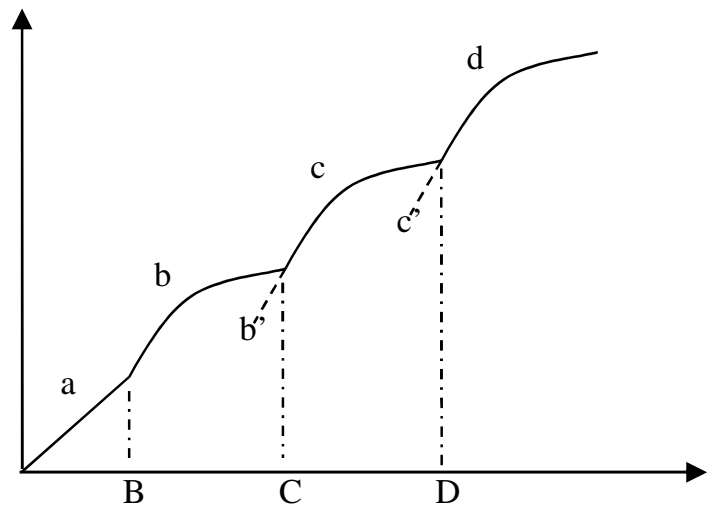

Deviation from effective. balanced state

Figure 3. Self-organization Evolution Mechanism of Chao Lake Environmental Protection Policy

\subsection{Self-organization Evolution Dynamics of Chao Lake Environmental Protection Policy}

The premise of self-organization evolution of Chao Lake environmental protection policy includes: system openness, away from equilibrium state, nonlinear action and fluctuation. Therefore, the motivation of selforganization evolution comes from the nonlinear interaction among various subsystems in the system: competition and coordination. Specifically, the dynamic factors of self-organization evolution include the following aspects: 
(1) Chao Lake economic growth, social transformation and environmental degradation and other external pressures. In the exploration stage, the proportion of industry in Chao Lake is low, water pollution is not serious, so the government's management of Chao is limited to local environmental management, environmental policy also focuses on the comprehensive utilization of fishery resources. In the establishment stage, with the deepening of reform and opening up, the development of township enterprises, the improvement of industrialization and the increase of population, Chao water quality gradually deteriorated, implementing the "first pollution control" policy concept, the period of environmental policy, Only emphasis on the protection of water sources to ensure that urban residents drinking water safety. As the environmental policy of "to treat only where the pain is", coupled with the further acceleration of economic development, Chao Lake environmental protection continues to deteriorate, therefore, in the formation stage, Chao Lake environmental protection policy is numerous, the contents of the point source control and the end Governance-based, but still not out of the "side of pollution control" of the cycle. As the trend towards deterioration of water quality in Chao Lake is effectively controlled, the government recognizes that the economic model at the expense of the environment is unsustainable and will in turn erode the economic and social development that has been achieved. As a result, Chao Lake environmental protection policy has entered the stage of environmental priority and protection priority. The policy focus is also on the combination of point source control and non-point source control, and the combination of end control and prevention and control(Bao,2007).

(2) From their own level and the level of policy learning. Chao Lake environmental policy philosophy and focus is constantly adjusted, one of the important reasons is the last stage of the policy of self-reflection. Due to the stability of the policy and lag, a stage of the policy effect can not be seen immediately. For example, in order to prevent the river water intrusion, in 1959 and 1960 has built the Yuxi brake and Chao gate, to the 80's, the negative effect of the policy gradually emerged - because the only Tongjiang River was cut off, Chao gradually by a water Shallow water lakes into artificial controlled semi-enclosed waters, which directly affects the next stage of policy development.

In addition, the top-down government management system also led Chao Lake environmental protection policy to actively study the national environmental policy. " Chao Lake Water Resource Protection Regulations " (1987) was enacted on the basis of the Environmental Protection Law (for trial implementation) (1979) and the Water Pollution Control Act (1984). With the promulgation of the Environmental Protection Act of 1989, the first revision of the Water Pollution Control Act of 1996 and the Decision of the State Council on Several Issues Concerning Environmental Protection (1995), Chao Lake Water Pollution Prevention Regulations (1998) was subsequently developed. In 2014, the comprehensive revision of the Ordinance was in line with the Environmental Protection Act of 2014, the Second Water Pollution Control Act of 2008, the Decision of the State Council on the Implementation of the Scientific Outlook on Development to Strengthen Environmental Protection "closely related(Li,2014).

(3) Chao Lake environmental protection management tool costs. In the exploration stage, both the government and the Supervised Entities lack of awareness of environmental protection, management is basically no cost, the relationship between the two is also in a state of mutual influence. As the government began to attach importance to environmental protection work, administrative control tools were heavily introduced into the Chao Lake environmental protection management policy, which is characterized by short-term effect is significant, but in the long run, to encourage the end of governance not only increased government regulation Costs also lead to the management of the relative marginal cost of governance is unbearable, contrary to the policy situation has occurred, the relationship between the two in a negative state of conflict.

In order to reduce the policy cost, the government began to use water pollution management, resource tax, government subsidies and other market-oriented tools for environmental protection management, driven by economic interests, the management of the relative choice of different ways to meet the policy requirements, the relationship between the two Active state of cooperation. With the people-oriented concept of environmental management gradually enjoys popular support, public voluntary participation tool also came into being. This policy tool still follows the principle of maximizing economic benefits. As the relative position of people in the policy relationship has changed from the object to the main body, coupled with the willingness to pay their own environment and the effect of conscience, the marginal cost of government environmental management has been reduced, The corresponding increase in the total income, between the two has formed a mutual trust based on the benign interaction.

\subsection{Self-organization Evolution Path of Chao Lake Environmental Protection Policy}

The play of the self-organizational evolutionary dynamics of Chao Lake environmental protection policy, that is, the process of policy development from disorder to order, is achieved through bifurcation and environmental 
choice. Bifurcation refers to the evolution of self-organization into a trend when the system enters the evolutionary dynamic threshold (threshold). Even in the same environment, the system may have different stable states, and the possible equilibrium states will follow the order. The parameters extend to very different evolutionary branches. So forks mean different evolution paths. But the fork just provides a possibility that the path of the criterion change is unique due to the role of environmental choice. The environment always chooses the fluctuations that suit him. At the bifurcation point, the environment induces the slight fluctuations suitable for him to develop in the direction he has specified. The micro fluctuations form a huge fluctuation under the nonlinear amplification of the system, locking One possibility (Figure 4).

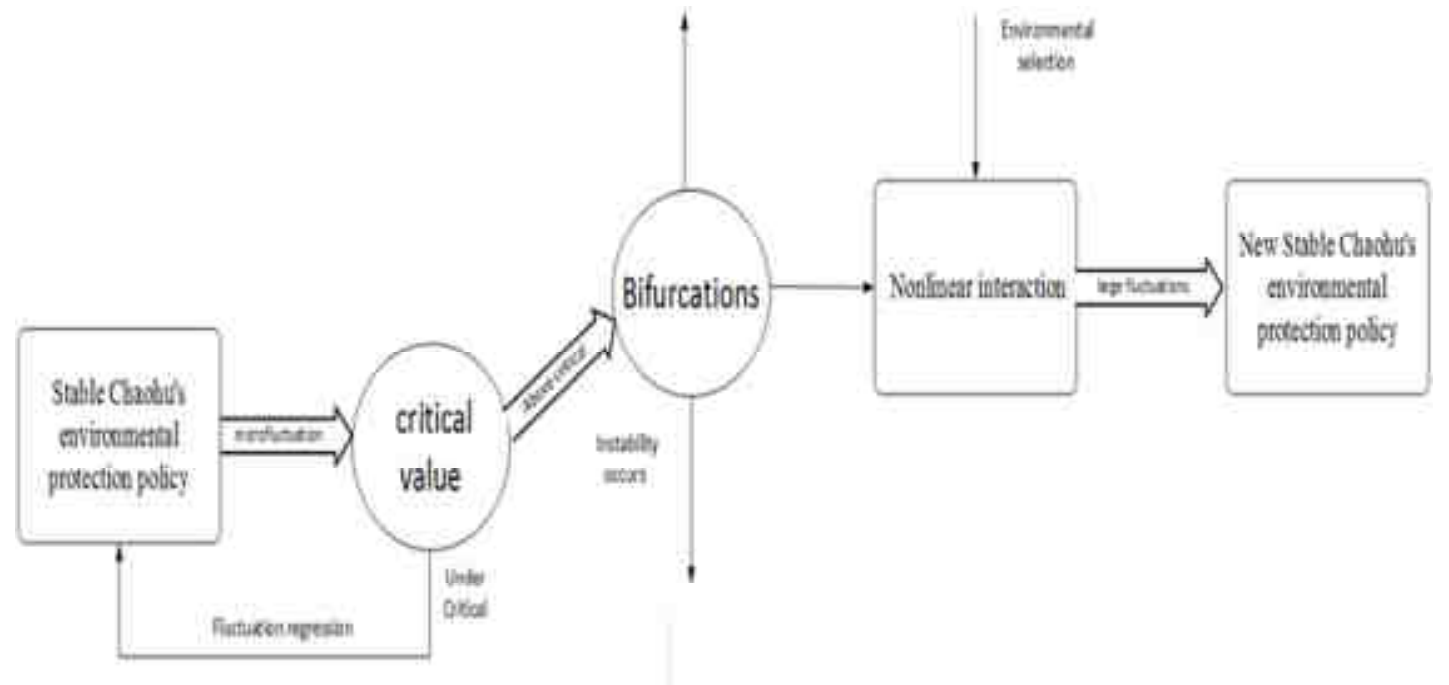

Figure 4. Self-organization Evolution Path of Environmental Chao Lake Protection Policy

\section{Prediction of Development Trend of Chao Lake Environmental Protection Policy}

Using the result of how the self-organization evolution mechanism operate, we can give a prediction of development trend of Chao Lake environmental protection policy as follows:

\subsection{Construction of ecological civilization}

The future environmental protection policy of Chao Lake should integrate ecological civilization construction into all aspects and the whole process of economic construction, political construction, cultural construction, social construction, and keep the priority of conservation priority and natural restoration as the basic policy. Development, low-carbon development, recycling as the basic way, adhere to the deepening of reform and innovation as the basic driving force, adhere to the cultivation of ecological culture as an important support to achieve ecological benefits, economic and social benefits win-win.

\subsection{Introduce cost-benefit policy analysis methods}

Cost-benefit analysis (CBA) refers to a methodological framework for judging and evaluating the efficiency of resource allocation for projects (or programs) and investments in public or non-profit sectors based on the discounted benefits and the magnitude of the cost. The costs of environmental protection policy in Chao Lake include the cost of development, the direct and indirect costs of implementation, the cost of policy violation, the opportunity cost of implementation, the marginal cost and so on. Specific benefits include economic, social and environmental benefits, of which social and environmental benefits can be monetized. By comparing the costeffectiveness of various policy options, the ultimate goal of selecting the optimal program is reached.

\subsection{Reconstruction of environmental protection management system}

"Major basin water pollution control plan (2016-2020)" (2012) has reflected the central government to strengthen the Chao and other key watershed to strengthen the regulatory trend. Reconstruction of environmental protection management system, not only to strengthen the local government environmental protectional management responsibilities, strengthen the coordination of the department, the central government should also be a single GDP for the performance evaluation standards into a green GDP as the center of the comprehensive assessment index system. The leading cadres who disregard the blind decision of the ecological environment and cause the deterioration of the environmental protection quality and cause serious consequences shall be recorded, depending on the seriousness of the case, given the handling of the organization or the disciplinary action of the 
party discipline and discipline, and shall be held accountable for life and shall not be transferred Important job or promotion.

\subsection{Form a multi-center governance policy mechanism}

Whether it is administrative control tools, or economic stimulus tools or public participation tools, have their inherent shortcomings and deficiencies, therefore, the future of Chao Lake environmental protection policy should be used in combination: adhere to the government market coordination, focus on Reform and innovation; adhere to the full accordance with the law to promote the implementation of the most stringent environmental protection system; adhere to the implementation of the responsibility of all parties, strict assessment of accountability; adhere to the people to participate in promoting the protection of the environment everyone is responsible for the formation of "government guidance, enterprise governance, market- Participation "of the multi-center governance environment policy mechanism(Qin,2007).

\subsection{The full implementation of environmental protection policy}

First, water resources protection and water quality management combined. Mainly including groundwater water abstraction permit management, section flow and water quality unified supervision, water conservation, soil erosion prevention and other measures. Second, the combination of lake management and river management, including land area straight sewage interception, improve the inferior $\mathrm{V}$ into the lake water quality, through the "Yangtze River Jiyuan" ecological water and other measures. Third, the combination of pollution prevention and ecological restoration. Including ecological dredging of Chao sediment, lake shoreline ecosystem restoration, feeding algae fish for biological manipulation and other measures. Fourth, point source management and nonpoint source management combined. Mainly including the adjustment of agricultural industry structure, the treatment of pollutants, interception of agricultural tail water and other measures.

\subsection{Strict environmental law enforcement supervision}

The vitality of the policy lies in the implementation of strict environmental law enforcement supervision, is to improve the performance of Chao Lake environmental protection management of the fundamental guarantee. Specific include the following aspects: First, cultivate talents. Strengthen environmental monitoring, environmental monitoring, environmental emergency and other professional and technical training, strict implementation of law enforcement, monitoring and other personnel certificates system. Second, improve the river collaboration mechanism. Watershed upstream and downstream governments at all levels, between departments to strengthen coordination and coordination, regular consultation, the implementation of joint monitoring, joint law enforcement, emergency linkage, information sharing. Third, improve the environmental protection monitoring network. Unified planning to set the monitoring section, to enhance the drinking water source water quality monitoring, aquatic biological monitoring, ground-environmental protectional monitoring, chemical substances monitoring and environmental risk prevention and control technical support capacity. Fourth, open monitoring information. (The county, district) water quality status, the focus of sewage units to the public to produce the main pollutant name, emission patterns, emission concentration and total, excessive emissions, take the initiative to accept social supervision.

\subsection{Cultivate ecological culture}

In addition to improving the implementation of the government, to cultivate the ecological environment of the whole society is also the future development of Chao Lake environmental protection policy one of the direction. First of all, it is necessary to carry out the ecological civilization education covering the whole society, raise public awareness of conservation, environmental awareness, ecological awareness, so that ecological civilization become the mainstream values of society. The second is to cultivate a green lifestyle, to carry out green life action, to promote the people in the clothing, food, shelter, travel, travel and other aspects of thrifty, green lowcarbon, civilized and healthy way to change. The third is to encourage public participation. Sound report, hearings, public opinion and public supervision, environmental public interest litigation system, support the construction of various types of social organizations in the field of ecological civilization development, build a social action system of universal participation(Ye,2013).

\section{References}

Bao,G.X.\& He,X.L.(2007).Research and Countermeasure of Environmental Governance - Reflection on Environmental Pollution Control in Lanzhou.Science and Technology Management,12, 129-132.

Guo,Q.F.(2014)."Chao Lake Water Pollution Prevention Regulations" revised tracking.Jianghuai rule of law, 17,8-10. 
H.Haken.(1991).Synergetic computers and recognition-a top-down approach to neural nets.Berlin:SpringerVerlag.

John W. Kingdom.(2004).Agenda choice and public policy (pp. 225). Beijing: Renmin University Press

Li,W.W.(2014).China's environmental governance policy efficiency,evalaution and industrial pollution control policy recommendations.Technology Management Research,17,20-26.

P. A. Sabatier.(1998). The Advocacy Coalition Framework: Revisions and Relevance to Europe.Journal of European Public Policy,01.

Qian, X. S.(1981).Science of system,thinking and body. Journal of Nature, 01,3-9.

Qin, Y.\&Xu G. (2007).Changes in environmental policy tools and its development trend [J]. Reform and Strategy ,12,51-54.

S. Walgrave\& F. Varone.(2008). Punctuated Equilibrium and Agenda- Setting: Bringing Parties Back in: Policy Change after the Dutroux Crisis in Belgium.Governance: An International Journal of Policy, Adm inistration, and Institutions, 03 .

YE, H.W. \&GAO,Y.W.(2013).Characteristics and Development Trend of Environmental Policy in China.Journal of Theoretical Studies, 04,92-94.Arai, T., Aiyama, Y., Sugi, M. \& Ota, J. (2001), "Holonic Assembly System with Plug and Produce", Computers in Industry 46, Elsevier, 289-299. 